Full length article

\title{
European sea bass brain DLB-1 cell line is susceptible to nodavirus: A transcriptomic study
}

\author{
Elena Chaves-Pozo ${ }^{\mathrm{a}}$, Isabel Bandín ${ }^{\mathrm{b}}$, José G. Olveira ${ }^{\mathrm{b}}$, Anna Esteve-Codina ${ }^{\mathrm{c}, \mathrm{d}}$, \\ Jèssica Gómez-Garrido ${ }^{c, d}$, Marc Dabad ${ }^{c, d}$, Tyler Alioto ${ }^{c, d}$, M. Ángeles Esteban ${ }^{\mathrm{e}}$, Alberto Cuesta ${ }^{\mathrm{e}, *}$

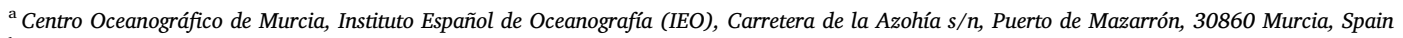 \\ b Departamento de Microbiología y Parasitología, Instituto de Acuicultura, Universidade de Santiago de Compostela, Campus Vida, Santiago de Compostela, Spain \\ ${ }^{\mathrm{c}}$ CNAG-CRG, Centre for Genomic Regulation (CRG), Barcelona Institute of Science and Technology (BIST), Baldiri i Reixac 4, 08028 Barcelona, Spain \\ ${ }^{\mathrm{d}}$ Universitat Pompeu Fabra (UPF), Barcelona, Spain \\ e Fish Innate Immune System Group, Department of Cell Biology and Histology, Faculty of Biology, Campus Regional de Excelencia Internacional "Campus Mare Nostrum”, \\ University of Murcia, 30100 Murcia, Spain
}

\section{A R T I C L E I N F O}

\section{Keywords:}

Nodavirus

European sea bass

Brain

DLB-1 cell line

Interferon

Transcriptomic

\begin{abstract}
A B S T R A C T
Viral diseases are responsible for high rates of mortality and subsequent economic losses in modern aquaculture. The nervous necrosis virus (NNV) produces viral encephalopathy and retinopathy (VER), which affects the fish central nervous system. It is considered one of the most serious viral diseases in marine aquaculture, the European sea bass (Dicentrarchus labrax) being amongst the most susceptible. We have evaluated the European sea bass brain derived cell line (DLB-1) susceptibility to NNV genotypes and evaluated its transcriptomic profile. DLB-1 cells supported NNV gene transcription and replication since strains belonging to the four NNV genotypes produce cytopathic effects. Afterwards, DLB-1 cells were infected with an RGNNV strain, the one which showed the highest replication, for 12 and $72 \mathrm{~h}$ and an RNA-seq analysis was performed to identify potential genes involved in the host-NNV interactions. Differential expression analysis showed the up-regulation of many genes related to immunity, heat-shock proteins or apoptosis but not to proteasome or autophagy processes. These data suggest that the immune response, mainly the interferon (IFN) pathway, is not powerful enough to abrogate the infection, and cells finally suffer stress and die by apoptosis liberating infective particles. GO enrichment also revealed, for the first time, the down-regulation of terms related to brain/neuron biology indicating molecular mechanisms causing the pathogenic effect of NNV. This study opens the way to understand key elements in sea bass brain and NNV interactions.
\end{abstract}

\section{Introduction}

Nervous necrosis virus (NNV), a member of the Family Nodaviridae, Genus Betanodavirus, which affects more than 130 marine and freshwater fish species, is one of the most devastating marine fish viruses worldwide and a serious economic threat to aquaculture [1]. NNV is a naked, icosahedral virus of $25-30 \mathrm{~nm}$, composed of 2 positive singlestranded RNA segments, RNA1 and RNA2, which are capped but not polyadenylated. The virus infects cells from the brain, spinal cord and retina causing viral encephalopathy and retinopathy (VER) leading to mortality rates of up to $100 \%$ in many fresh and marine water fish species [2]. NNV strains are currently classified in four different genotypes: striped jack nervous necrosis virus (SJNNV), tiger puffer nervous necrosis virus (TPNNV), barfin flounder nervous necrosis virus (BFNNV) and red-spotted grouper nervous necrosis virus (RGNNV) [3].
Since the first isolation of NNV in the SSN-1 cell line from Channa striatus [4] and subsequent setup of its E -11 cell line clone [5], other fish cell lines have been reported to support NNV replication. Regarding very susceptible fish species such as groupers (Epinephelus spp.), the GF1 cell line derived from fins [6] has been one of the most used for NNV infections.

Several aspects of NNV-host interaction have been discovered using fish cell lines, namely SSN-1 and GF-1 cells. Focusing on the cell membrane, it has been reported that NNV particles interact with $\mathrm{N}$ glycosylated receptors rich in sialic acid in SNN-1 cells or with the heatshock cognate protein 70 (HSC70), belonging to the heat shock protein (HSP) family, in GF-1 cells $[7,8]$. In addition, it was suggested that NNV entered the cell via the spherical pit and membrane ruffling leading to both micro- and macro-pinocytosis pathways [7], though more recently it has been documented that NNV virus like particles (VLP) entered into

\footnotetext{
* Corresponding author.

E-mail address: alcuesta@um.es (A. Cuesta).
} 


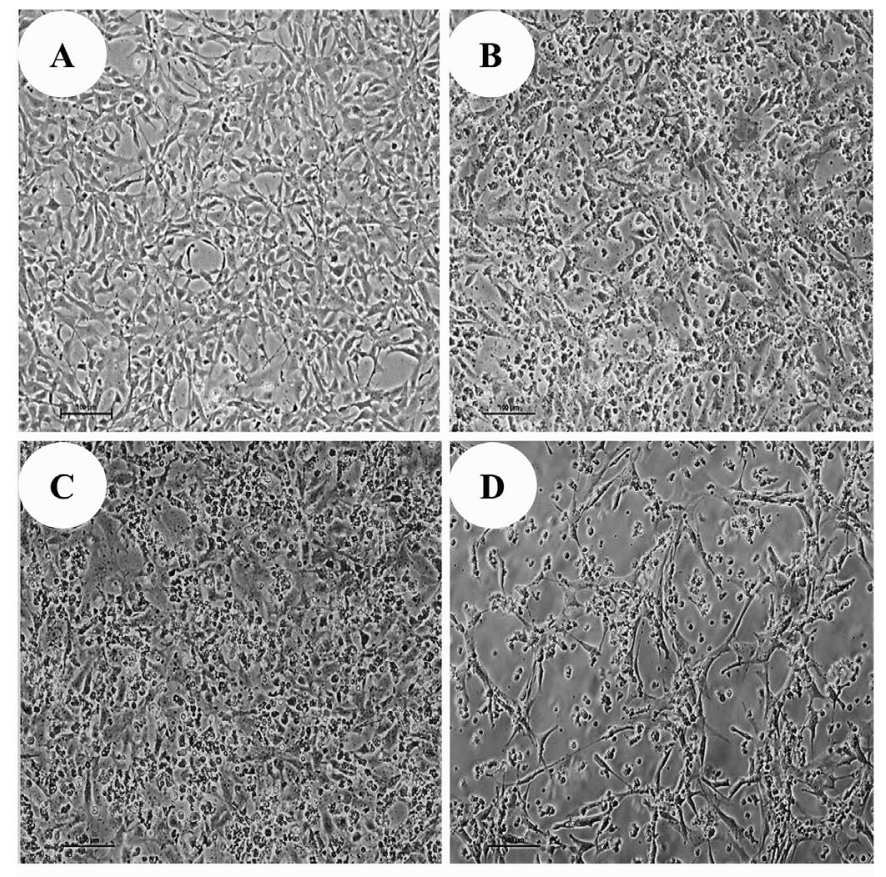

E

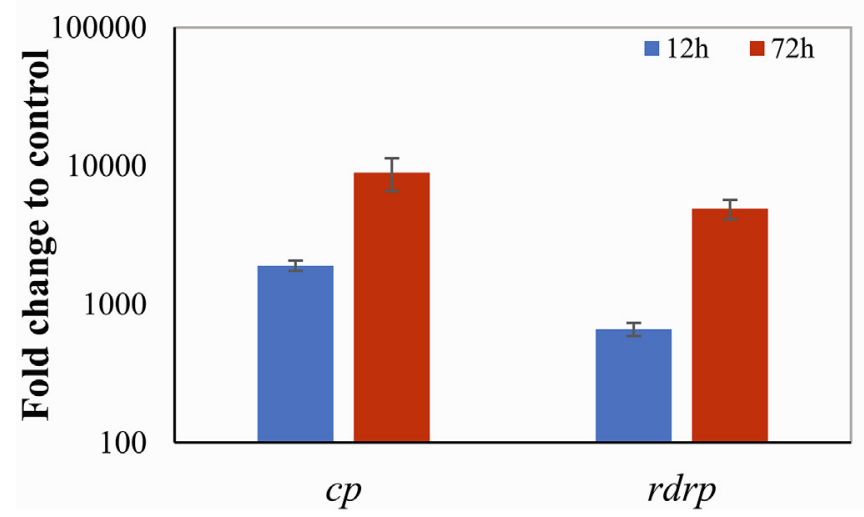

Fig. 1. Nodavirus replicates in the DLB-1 cell line and produces cytopathic effect. A-D. Phase contrast microscope images from DLB-1 cultures incubated at $25^{\circ} \mathrm{C}$ with RGNNV genotype: mock-infected (A), $24 \mathrm{~h}$ (B), $72 \mathrm{~h}$ (C) or $96 \mathrm{~h}$ (D). Bars correspond to $100 \mu \mathrm{m}$. E. Transcription of viral RNA-dependent RNA polymerase ( $r d r p)$ and capsid ( $c p$ ) genes in DLB-1 cultures after 12 or $72 \mathrm{~h}$ of infection. Bars represent the relative gene expression mean \pm SEM ( $n=3$ replicates).

susceptible cells by clathrin-mediated endocytosis [8]. Once inside the cell, the virus starts its replication by rendering the host machinery to its own benefit. At early infection stages, RNA1 produces the RNA-

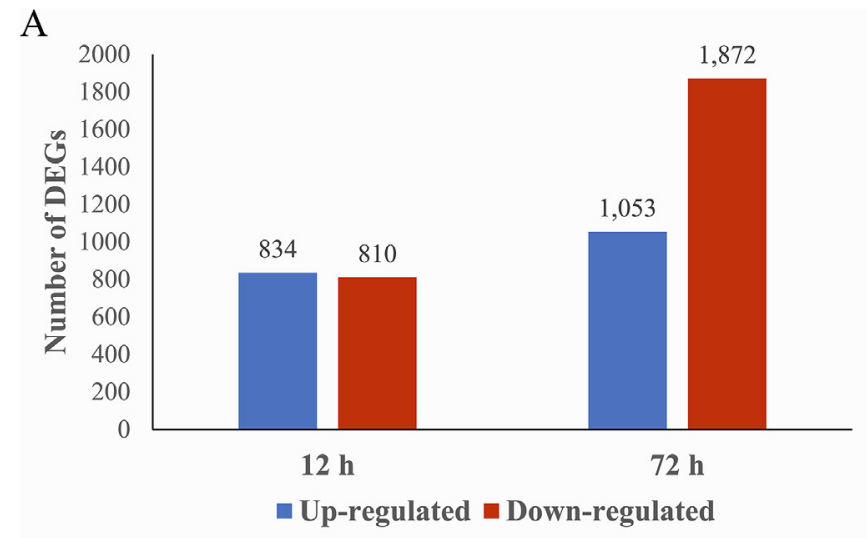

B. DEGs FC>2

\section{DEGs $\mathrm{FC}<0.5$}
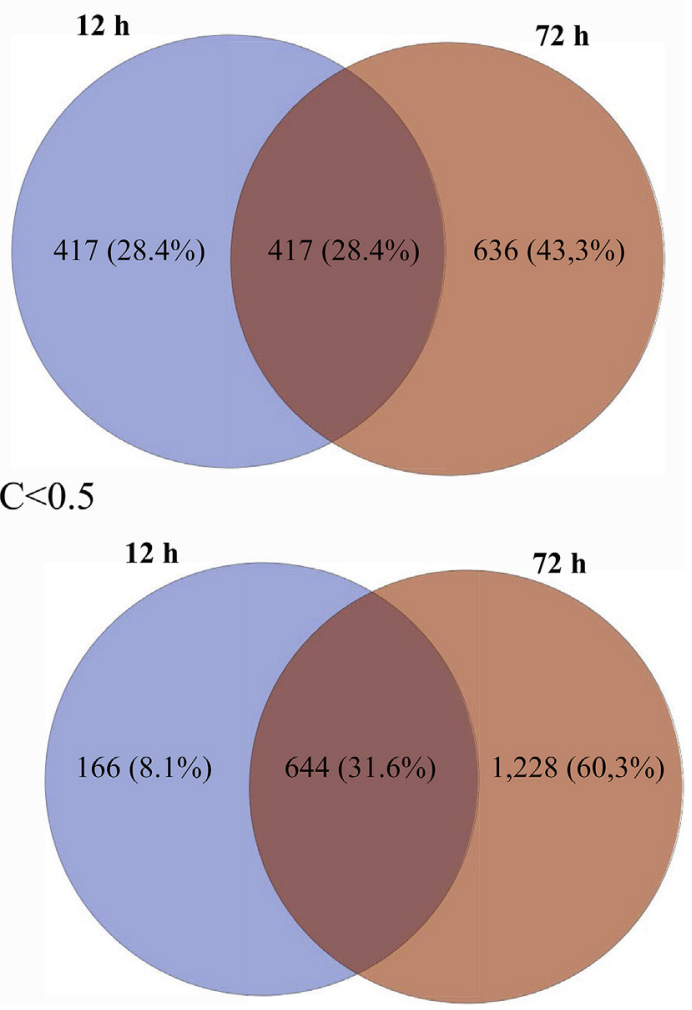

Fig. 2. Differentially expressed genes (DEGs) in DLB-1 cells upon NNV infection. A. Bar plots showing the number of up-regulated and down-regulated genes in DLB-1 cells after 12 or $72 \mathrm{~h}$ of NNV infection. Venn diagrams of upregulated (B) and down-regulated (C) genes.

Table 1

DLB-1 susceptibility to the four Betanodavirus genotypes.

\begin{tabular}{|c|c|c|c|c|c|c|}
\hline \multirow[t]{2}{*}{ Genotype } & \multirow[t]{2}{*}{ Strain } & \multicolumn{2}{|c|}{ Cell culture at $20^{\circ} \mathrm{C}$} & \multicolumn{3}{|c|}{ Cell culture at $25^{\circ} \mathrm{C}$} \\
\hline & & $\mathrm{CPE}$ & RNA copy number ${ }^{\mathrm{b}}$ & $\mathrm{CPE}$ & RNA copy number ${ }^{\mathrm{d}}$ & Titer $^{\mathrm{e}}$ \\
\hline RGNNV & SGWak97 & $-/-^{\mathrm{a}}$ & $4 \pm 0.14 / 4.25 \pm 0.1$ & $+/+^{\mathrm{c}}$ & $5.51 \pm 0.11 / 6.64 \pm 0.15$ & $4 \pm 0.25 / 5.5 \pm 0$ \\
\hline SJNNV & SJNag97 & $-/-$ & $3.84 \pm 0.16 / 4.09 \pm 0.11$ & $+/+$ & $5.29 \pm 0.14 / 6.37 \pm 0.08$ & $3.75 \pm 0.14 / 5 \pm 0.14$ \\
\hline BFNNV & JFIwa98 & $-1-$ & $4.03 \pm 0.12 / 4.35 \pm 0.14$ & $+/+$ & $5.12 \pm 0.16 / 6.26 \pm 0.1$ & $3.75 \pm 0.14 / 5 \pm 0.14$ \\
\hline TPNNV & TPKag93 & $-1-$ & $3.97 \pm 0.2 / 4.3 \pm 0.16$ & $+/+$ & $4.85 \pm 0.14 / 6.11 \pm 0.12$ & $3.25 \pm 0.25 / 4.75 \pm 0.14$ \\
\hline RGNNV/SJNNV & SpSs-IAusc160.03 & $-/-$ & $3.92 \pm 0.11 / 4.21 \pm 0.09$ & $+/+$ & $5.37 \pm 0.12 / 6.54 \pm 0.09$ & $3.75 \pm 0.14 / 5.25 \pm 0$ \\
\hline
\end{tabular}

a, no cytopathic effect (CPE) observed in the first inoculation or after subcultivation on $25 \mathrm{~cm}^{2}$ flasks; b, $\log _{10}$ (mean RNA1 copies/ml) and standard deviation detected on the first culture/subculture; c, observation of cytopathic effect after first culture/subculture; $d$, $\log _{10}$ (mean RNA1 copies/ml) and standard deviation detected on the first culture/subculture e, $\log _{10}\left(\right.$ mean $\mathrm{TCID}_{50} / \mathrm{ml}$ ) and standard deviation on the first culture/subculture. 


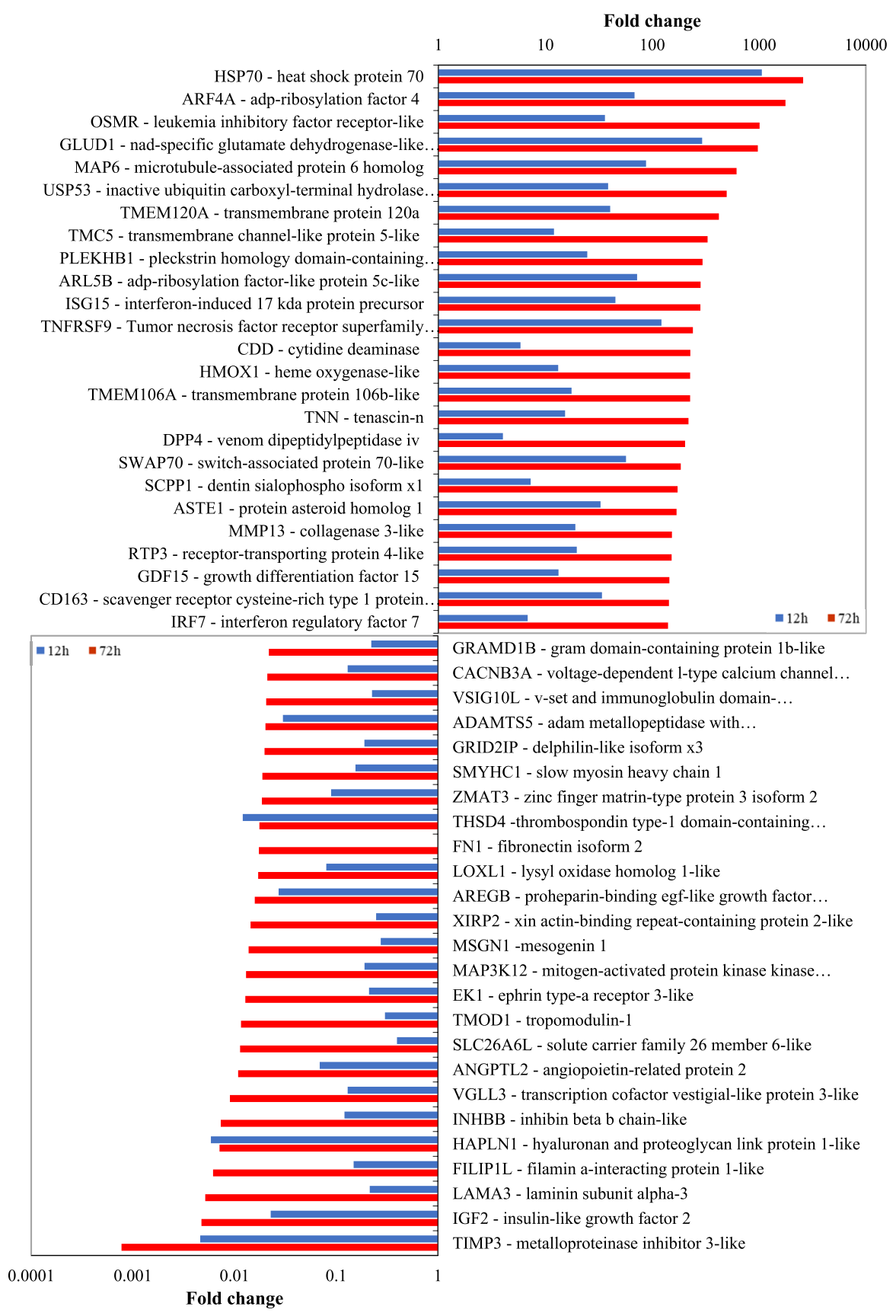

Fig. 3. Fold change of the 25 top up-regulated and down-regulated genes in the European sea bass DLB-1 cells after NNV infection.

dependent polymerase (RdRp) but also two other proteins in the subgenomic RNA3 fragment, B1 and B2, which are mainly involved in viral cycle regulation and do not form part of the virion [9]. Thus, early production of B1 has anti-necrotic effects on host cells [10] and arrests them in the G1/S cycle phase [11] increasing the cellular shelf-life. On the contrary, the $\mathrm{B} 2$ protein acts by inhibiting the interfering RNA protection system from the cells [12], induces the production of reactive oxygen species (ROS) [13] and favours both apoptosis and necrosis cell death $[14,15]$. Although further functional studies are necessary to know the precise mechanisms behind NNV-fish cell interactions, the use of massive transcriptomic techniques is throwing some light onto this issue. Thus, RGNNV infection either in vitro or in vivo resulted in the differential expression of genes (DEG) related to the retinoic acid-inducible gene I (RIG-I) like receptors, interferon, apoptosis, oxidative phosphorylation, PI3K-Akt and MAPK signalling or endoplasmic reticulum stress among others [16-20].
Unfortunately, although several brain cell lines derived from different fish species have been obtained [21-26], reduced information is available at either transcriptional or functional levels in target tissues or derived-cell lines. These studies could represent valuable tools to understand virus neurotropism and actions on the central nervous system. Therefore, in this study we have evaluated the capacity of the DLB1 cell line, derived from European sea bass (Dicentrarchus labrax) brain [27], to support NNV replication and also analysed their transcriptome by means of the RNA-seq platform. Results will be discussed to throw some light on NNV-brain cells interaction and pathogenesis.

\section{Materials and methods}

\subsection{DLB-1 cell line and nodavirus}

The DLB-1 cell line obtained from the European sea bass brain was 

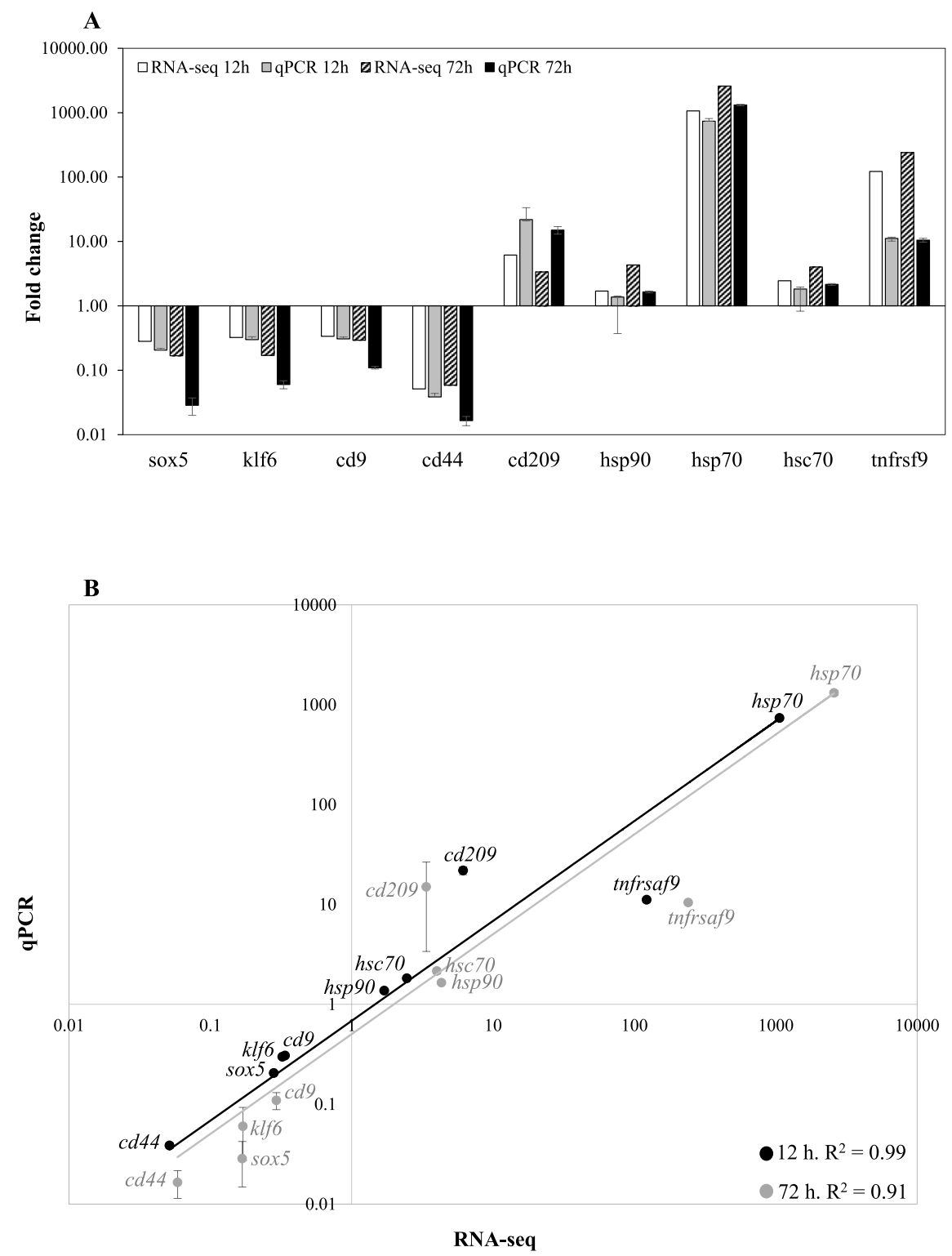

Fig. 4. Validation of the RNA-seq data by means of the qPCR. A. Bar plot showing the fold change in the expression of selected genes in DLB-1 cells after 12 or 72 of NNV infection compared to control cells as determined by qPCR or RNA-seq. B. Plot represents the mean value for selected genes in each group. Data were fitted by linear regression and adjusting quality determined. For A and B plots, RNA-seq was conducted using a pool of 3 samples whilst the qPCR was done on the 3 individual samples. $\mathrm{qPCR}$ data are presented as the mean \pm SEM $(\mathrm{n}=3$ replicates $)$.

used [27]. Cell monolayers were grown at $25^{\circ} \mathrm{C}$ in L-15 Leibovitz medium containing $0.16 \% \mathrm{NaCl}, 15 \%$ foetal bovine serum (FBS), $20 \mathrm{mM}$ HEPES, $2 \mathrm{mM}$ glutamine, penicillin $(100 \mathrm{IU} / \mathrm{ml})$ and streptomycin $(100 \mu \mathrm{g} / \mathrm{ml})$ and subcultured by trypsinization every week.

Betanodavirus strains belonging to each of the four recognized genotypes as well as a reassortant strain were tested: SJNag97 (SJNNV), SGWak97 (RGNNV), JFIwa98 (BFNNV), TPKag93 (TPNNV) and SpSsIAusc160.03 (RGNNV/SJNNV) were used. Viruses were propagated using E-11 cell cultures [5]. Cell monolayers were grown in L-15 medium containing $5 \% \mathrm{FBS}$, penicillin $(100 \mathrm{IU} / \mathrm{ml})$ and streptomycin $(100 \mu \mathrm{g} / \mathrm{ml})$. Inoculated cells were incubated at $25^{\circ} \mathrm{C}$ up to a maximum of 7 days. When the cytopathic effect (CPE) became extensive, culture media were harvested and clarified by centrifugation at $3000 \mathrm{~g}$ for 15 min at $4{ }^{\circ} \mathrm{C}$ and stored at $-80^{\circ} \mathrm{C}$. Virus titration was conducted on monolayers of $\mathrm{E}-11$ cells in 96 -well plates using serial 10 -fold dilutions in triplicate. Plates were incubated for ten days at $25^{\circ} \mathrm{C}$. The $50 \%$ tissue culture infective dose $\left(\mathrm{TCID}_{50} / \mathrm{mL}\right)$ was then calculated [28].

\subsection{DLB-1 cells susceptibility to nodavirus}

DLB- 1 cells grown on $25 \mathrm{~cm}^{2}$-flasks were inoculated by duplicate with the NNV strains at a multiplicity of infection (MOI) of 0.1 . Virus samples were adsorbed at room temperature for $1 \mathrm{~h}$, then the inoculum was removed and fresh medium was added to the cells. Infected flasks were incubated at either 20 or $25^{\circ} \mathrm{C}$ and examined daily for the presence of the cytopathic effect (CPE). After 5-6 days, when the CPE was extensive, the supernatant from these cultures was collected and used to infect new flasks. The cultures showing no CPE were also subcultured by inoculating $0.1 \mathrm{ml}$ of the scraped cell suspension onto new cultures. The subcultivation was terminated after 5 days, when complete destruction was observed in most of the infected cultures, at $25^{\circ} \mathrm{C}$ and after 10 days at $20^{\circ} \mathrm{C}$. Viral titration was performed in $\mathrm{E}-11$ cells using 48-well plates as described above.

To determine the virus yield produced from the DLB-1 cell line, viral suspensions (crude virus) obtained from the flasks were subjected to RT-qPCR and viral titration. The infected cell cultures with no CPE were 


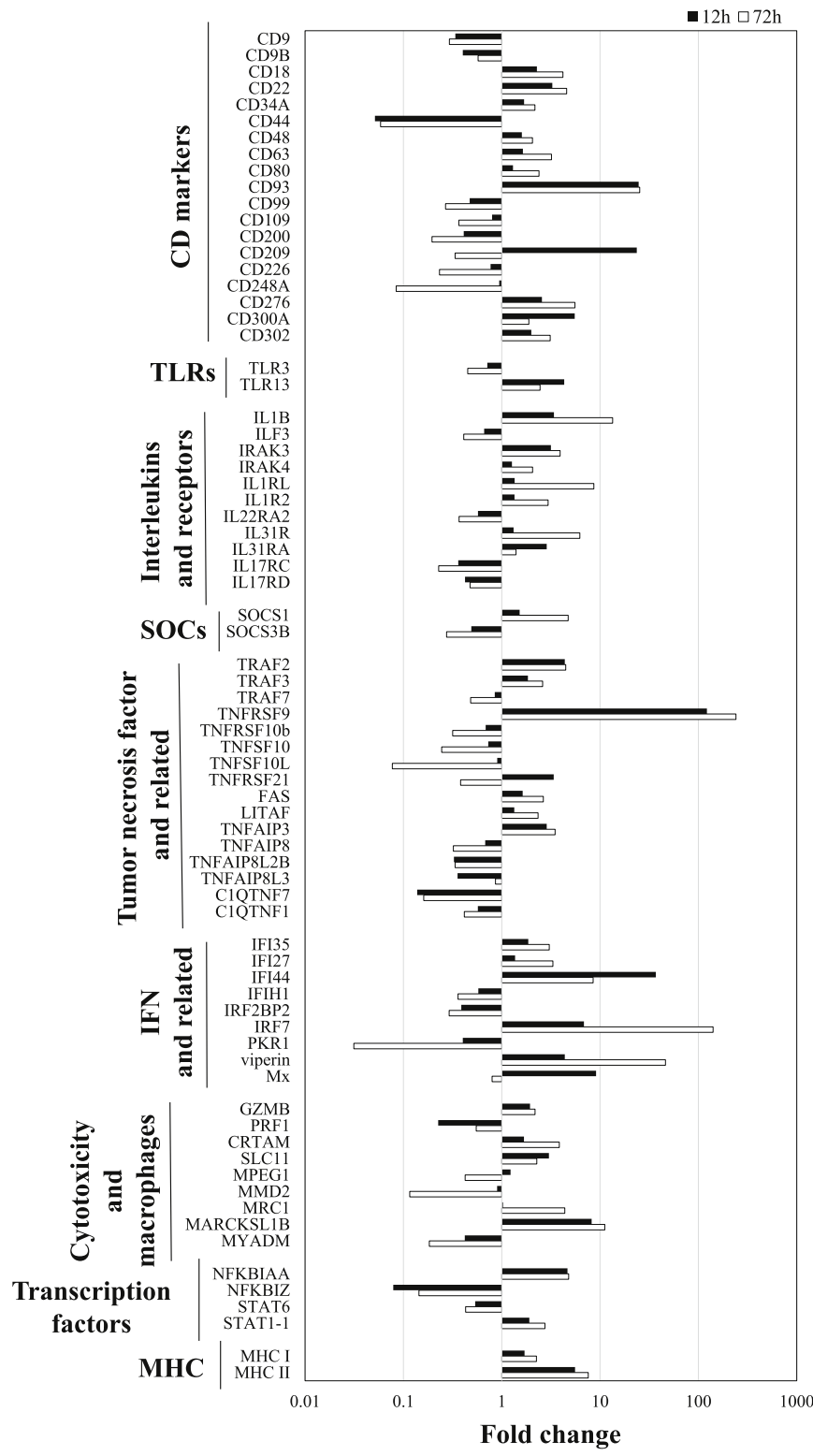

Fig. 5. RNA-seq differential expression of selected immune genes in the European sea bass DLB-1 cells after 12 or $72 \mathrm{~h}$ of NNV infection compared with control or uninfected cells. Only significant DEGs are included.

also subjected to RT-qPCR. To do this, RNA was extracted from $200 \mu \mathrm{l}$ from both CPE-positive and -negative cultures (crude virus or scrapped cell suspension, respectively) using the EZNA Total RNA I kit (Omega Biotek) in accordance with the supplier's protocol. Synthesis of complementary DNA (cDNA) was performed by mixing the viral RNA with random primers (Promega) and following the Superscript IV reverse transcriptase guidelines (Invitrogen). For quantitative real-time PCR (qPCR), reactions were processed with $2 \mu \mathrm{l}$ of cDNA samples in $20 \mu 1$ final volume using iQTMSYBR ${ }^{\circ}$ Green Supermix (Bio-Rad) and $200 \mathrm{nM}$ of each primer SnodR1 F/R [29]. All samples were tested in triplicate. A 10 -fold dilution series containing $10^{7}-10^{1}$ copies of a plasmid DNA containing the full-length cDNA sequence of SpSs-IAusc 160.03 RNA1 was used to create a standard curve.

\subsection{RNA-seq study}

\subsubsection{NNV infection}

DLB-1 cells were seeded in 6-well plates and inoculated with the betanodavirus SGWak97 strain in triplicate as above. $0 \mathrm{~h}$ infected cells were used as controls. After 12 or $72 \mathrm{~h}$ (when the CPE was extensive) of incubation at $25^{\circ} \mathrm{C}$, cells were recovered and the TRIzol LS reagent (Invitrogen) added.

\subsubsection{RNA isolation}

Total RNA was isolated using the PureLink RNA Mini Kit (Life Technologies) with on-column DNase treatment according to the manufacturer's instructions. The concentration and the quality of the RNA were analyzed using a Nanodrop ND1000 (Nanodrop Technologies) and Agilent 2100 Bioanalyzer (Agilent Technologies).

\subsubsection{Stranded mRNA library preparation and sequencing}

Total RNA from triplicate samples was equally pooled and used to prepare the libraries using the TruSeq ${ }^{\circ}$ Stranded mRNA LT Sample Prep Kit (Illumina Inc.) according to manufacturer's protocol. After poly-A mRNA enrichment, fragmentation, cDNA synthesis and ligation, the final library was constructed and validated on an Agilent 2100 Bioanalyzer with the DNA 7500 assay. Each library was then sequenced using TruSeq SBS Kit v3-HS (2x76bp length) on HiSeq2000 (Illumina) following the manufacturer's protocol and analysed as elsewhere [30].

\subsubsection{RNA-seq data processing and differential expression analysis}

RNA-seq paired-end reads were mapped against the DicLab assembly [30] with STAR [31] and genes were quantified with RSEM [32] using DicLab annotation [30]. A Fisher exact test was applied for the detection of differential expression between time points (12 or $72 \mathrm{~h}$ $\mathrm{NNV}$ infected $v s 0 \mathrm{~h}$ or control). Genes following these criteria were filtered and considered significant DEGs: $\Delta \mathrm{cpm}>5$ or $<-5$, FDR (false discovery rate) $<5 \%$ and absolute FC (fold change) $>2$ or $<0.5$. Gene ontology enrichment analysis of biological processes was performed with GOstats [33]. Protein-protein interaction networks were built up with the STRING database (https://string-db.org/).

\subsection{Validation of RNA-seq data with $q P C R$}

We evaluated the expression of selected genes using qPCR and the $2^{-\Delta \mathrm{CT}}$ method [34] to validate the RNA-seq data as previously [30]. To this end, individual total RNA from triplicates (not pooled) was used to generate the cDNA using the SuperScript III $^{\mathrm{TM}}$ RNAse H- Reverse Transcriptase (Invitrogen) and random hexamers (Invitrogen). qPCR was carried out with SYBR Green PCR Core Reagents (Applied Biosystems) in an ABI PRISM 7500 instrument (Applied Biosystems). To normalize the mRNA content the transcription of the house-keeping elongation factor 1-alpha (ef1a), ribosomal protein L13 alpha(l13a) and tubulin alpha (tuba) was determined and expressed as $2^{-\Delta \mathrm{Ct}}$, where $\Delta \mathrm{Ct}$ is determined by subtracting the house-keeping genes $\mathrm{Ct}$ value from the target Ct. The primers used are shown in Supplementary Table 1. Negative samples were also included.

\section{Results}

\subsection{All NNV genotypes replicate in the DLB-1 cell line}

Extensive CPE, after 4 days, to total destruction (after 6 days) was observed in the DLB-1 cell cultures infected with the four NNV strains incubated at $25^{\circ} \mathrm{C}$ as well as NNV gene expression (Fig. 1, Table 1). However, at $20^{\circ} \mathrm{C}$ neither CPE was observed in the cultures incubated nor qPCR data supported viral replication (Table 1). No statistical differences among NNV genotypes were observed regarding viral loads at $25^{\circ} \mathrm{C}$. However, as RGNNV showed high viral loads at $25^{\circ} \mathrm{C}$ and considering that European sea bass is naturally susceptible to this genotype, we incubated the DBL-1 cell culture with the SGWak97 strain for 12 or $72 \mathrm{~h}$ and used for the RNA-seq experiments. Besides the microscopic observation of the cultures, NNV transcription was confirmed in these samples by the detection of both $c p$ and $r d r p$ genes, which were up-regulated from 12 to $72 \mathrm{~h}$ (Fig. 1E). 
Table 2

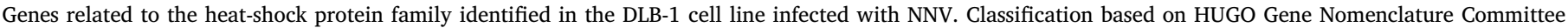
(HGNC). FC, fold change respect to the control; FDR, false discovery rate; *, undetected in control but expressed in NNV-infected.

\begin{tabular}{|c|c|c|c|c|c|c|c|}
\hline Approved Name & Approved Symbol & Synonyms & Acc. Number & FC $12 \mathrm{~h}$ & FC $72 \mathrm{~h}$ & FDR $12 \mathrm{~h}$ & FDR $72 \mathrm{~h}$ \\
\hline \multicolumn{8}{|l|}{ HSP70 family } \\
\hline $\begin{array}{l}\text { Heat-shock protein family A (Hsp70) member } \\
\text { 1A }\end{array}$ & HSPA1A & HSPA1, HSP70-1 & DLAgn_00212020 & 1064.58 & 2587.52 & 4E-05 & $1 \mathrm{E}-04$ \\
\hline Heat-shock protein family A (Hsp70) member 4 & HSPA4 & HS24/P52, HSPH2 & DLAgn_00045090 & 3.36 & 3.70 & $5 \mathrm{E}-05$ & $1 \mathrm{E}-04$ \\
\hline Heat-shock protein family A (Hsp70) member 5 & HSPA5 & GRP78, BiP & DLAgn_00131720 & 30.32 & 74.34 & $2 \mathrm{E}-05$ & 7E-05 \\
\hline Heat-shock protein family A (Hsp70) member 8 & HSPA8 & HSPA10, HSC71, HSC70, HSP73 & DLAgn_00033880 & 5.14 & 9.76 & 4E-05 & $1 \mathrm{E}-04$ \\
\hline Heat-shock protein family A (Hsp70) member 9 & HSPA9 & HSPA9B, GRP75, PBP74, mot-2, mthsp75 & DLAgn_00106140 & 3.43 & 5.34 & $9 \mathrm{E}-05$ & $2 \mathrm{E}-04$ \\
\hline $\begin{array}{l}\text { Heat-shock protein family A (Hsp70) member } \\
12 \mathrm{~A}\end{array}$ & HSPA12A & FLJ13874, KIAA0417 & DLAgn_00018000 & 1.13 & 0.28 & $6 \mathrm{E}-01$ & $5 \mathrm{E}-05$ \\
\hline $\begin{array}{l}\text { Heat-shock protein family A (Hsp70) member } \\
\quad 13\end{array}$ & HSPA13 & STCH & DLAgn_00030090 & 1.74 & 2.04 & $1 \mathrm{E}-05$ & $5 \mathrm{E}-05$ \\
\hline $\begin{array}{l}\text { Heat-shock protein family A (Hsp70) member } \\
\quad 14\end{array}$ & HSPA14 & HSP70-4, HSP70L1 & DLAgn_00205090 & 1.19 & 2.21 & 4E-04 & $6 \mathrm{E}-05$ \\
\hline \multicolumn{8}{|l|}{ HSP90 family } \\
\hline $\begin{array}{l}\text { Heat-shock protein } 90 \text { alpha family class A } \\
\text { member } 1\end{array}$ & HSP90AA1 & $\begin{array}{l}\text { HSPC1, HSPCA, Hsp89, Hsp90, FLJ31884, } \\
\text { HSP90N }\end{array}$ & DLAgn_00068070 & 22.78 & 34.10 & $8 \mathrm{E}-05$ & $2 \mathrm{E}-04$ \\
\hline $\begin{array}{l}\text { Heat-shock protein } 90 \text { alpha family class B } \\
\text { member } 1\end{array}$ & HSP90AB1 & HSPC2, HSPCB & DLAgn_00169960 & 1.29 & 1.16 & $8 \mathrm{E}-05$ & 2E-04 \\
\hline Heat-shock protein 90 beta family member 1 & HSP90B1 & HSP90BA, TRA1, GP96, GRP94 & DLAgn_00070720 & 1.70 & 4.32 & $2 \mathrm{E}-04$ & $6 \mathrm{E}-04$ \\
\hline TNF receptor associated protein 1 & TRAP1 & HSP75. HSP90L & DLAgn_00189970 & 1.19 & 1.55 & 3E-05 & $8 \mathrm{E}-05$ \\
\hline \multicolumn{8}{|l|}{ Small HSP family } \\
\hline Heat-shock protein family B (small) member 1 & HSPB1 & HSP27, HSP28, Hs.76067, Hsp25, CMT2F & DLAgn_00039710 & 12.67 & 18.57 & $8 \mathrm{E}-06$ & $5 \mathrm{E}-05$ \\
\hline Heat-shock protein family B (small) member 5 & HSPB5 & crystallin alpha B, CRYAB; CRYA2 & DLAgn_00001610 & 1.32 & 4.55 & $2 \mathrm{E}-05$ & $1 \mathrm{E}-09$ \\
\hline Heat-shock protein family B (small) member 6 & HSPB6 & & DLAgn_00064530 & 1.01 & 1.98 & 3E-02 & $5 \mathrm{E}-05$ \\
\hline Heat-shock protein family B (small) member 7 & HSPB7 & FLJ32389, Hsp20, PPP1R91 & DLAgn_00029000 & 53.28 & 1.18 & 7E-06 & $6 \mathrm{E}-01$ \\
\hline Heat-shock protein family B (small) member 8 & HSPB8 & cvHSP & DLAgn_00122020 & 1.36 & 3.70 & $2 \mathrm{E}-05$ & $6 \mathrm{E}-05$ \\
\hline Heat-shock protein family B (small) member 11 & HSPB11 & C1orf41, HSPCO34, PP25, IFT25 & DLAgn_00117650 & 0.84 & 1.42 & 2E-05 & $2 \mathrm{E}-02$ \\
\hline Heat-shock protein $30 \mathrm{kDa}$ & HSP30 & & DLAgn_00219140 & * & * & 7E7 & $5 \mathrm{E} 5$ \\
\hline \multicolumn{8}{|l|}{ Chaperonins } \\
\hline Heat-shock protein family D (Hsp60) member 1 & HSPD1 & SPG13, GroEL, HSP60 & DLAgn_00054840 & 2.31 & 5.21 & $5 \mathrm{E}-05$ & $1 \mathrm{E}-04$ \\
\hline $\begin{array}{l}\text { Heat-shock protein family E (Hsp10) member } 1 \\
\text { DNAJ (HSP40) family }\end{array}$ & HSPE1 & CPN10, GroES, HSP10, EPF & DLAgn_00054830 & 2.15 & 6.42 & 3E-05 & $8 \mathrm{E}-05$ \\
\hline $\begin{array}{l}\text { DnaJ Heat-shock protein family (Hsp40) } \\
\text { member A1 }\end{array}$ & DNAJA1 & HSJ2 & DLAgn_00182280 & 2.34 & 2.35 & $1 \mathrm{E}-05$ & $5 \mathrm{E}-05$ \\
\hline $\begin{array}{l}\text { DnaJ Heat-shock protein family (Hsp40) } \\
\text { member C4 }\end{array}$ & DNAJC4 & HSPF2 & DLAgn_00108040 & 0.93 & 1.91 & $3 \mathrm{E}-05$ & 2E-04 \\
\hline
\end{tabular}

\subsection{Differential gene expression in DLB-1 cells upon NNV infection}

The RNA-seq analysis resulted in $1.12-1.63 \times 10^{8}$ reads, more than $95 \%$ of which were unique sequences and lower than $8.89 \%$ unmapped (Supplementary Table 2). These reads were assembled and annotated in a total of 13,025 genes which were assigned to a functional category [30]. Gene ontologies were determined and used to extract more relevant and applicable conclusions of the differential expression analysis by gene ontology enrichment.

After evaluation of DEGs (Supplementary Table 3), we obtained 1645 DEGs after $12 \mathrm{~h}$ of infection with respect to controls with very similar number of genes up- and down-regulated (834 and 810, respectively) (Fig. 2A). On the other hand, $72 \mathrm{~h}$ after infection, the number of DEGs was increased up to 2,925, of which 1053 were upregulated and 1872 down-regulated. Interestingly, amongst the up- or down-regulated genes at the two sampling times most of them corresponded to unique genes at $72 \mathrm{~h}$ of infection (Fig. $2 \mathrm{~B}$ and C). We selected the top 25 most DE genes at $72 \mathrm{~h}$ of infection and compared them to the same at $12 \mathrm{~h}$ of infection resulting higher regulations at $72 \mathrm{~h}$ (Fig. 3). Among the most up-regulated genes we found genes related to protein stress (HSP70), immunity (ISG15, TNFRSF9, CD163, DPP4, SWAP70 or IRF7), vesicle transport (ARF4A, ARL5B), proteasome (USP53), cytoskeleton (MAP6) or metabolism (GLUD1, CDD, HMOX1) while most of the down-regulated genes belong to cellular metabolism, cell cycle arrest and cytoskeleton. In addition, though we made the RNA-seq analysis with pooled RNA samples, we tested the individual RNA samples at each infection time by qPCR for some selected genes. Data were plotted and the regression analysis revealed an $\mathrm{R}^{2}=0.99$ at $12 \mathrm{~h}$ and an $\mathrm{R}^{2}=0.91$ at $72 \mathrm{~h}$ demonstrating very good correlation between pooled RNA-seq and individual qPCR data (Fig. 4).

\subsection{NNV infection induces immunity, cellular stress and apoptosis}

A GO enrichment analysis was also performed with these up- or down-regulated genes to ascertain their categorization in the biological process (Supplementary Table 4). In all cases, the most represented GO terms are associated with cellular and/or metabolic processes. Apart from the general cellular metabolism, we will focus on genes related to immunity (mainly interferon), cellular response to stress and cell death since NNV infection results in DLB-1 cell death causing extensive CPE. Regarding the antiviral immune response, we have identified some important genes in DLB-1 cells upon NNV infection such as, but not limited to, Toll-like receptors (encoding TLR5m, TLR8, TLR13 and TLR18), the IFN pathway (encoding IRF2, IRF3, IRF6, IRF7, IRF8, Viperin, Mx, PKR, IFI44, IFI17/ISG15, IFIT2, IFI35, IFI30 or IFIH1/ MDA5), clusters of differentiation (CD163, CD93, CD22, CD63, CD34A, CD9, CD99, CD226, CD200 or CD44), tumor necrosis factor and related proteins (TRAF2, TRAF3, TRAF7, TNFRSF9, TNFRSF21, TNFSF10 or Fas), suppressor of cytokine signalling (SOCS1 or SOCS3B), interleukins and their receptors (IL1B, IRAK3, IRAK4, IL1R, IL17R, IL31R or IL22R), genes related to the cytotoxic cells and macrophages (CRTAM, GZMB, PRF1, MPEG1, or MRC1), transcription factors (related to NF-kB, STAT6 and STA1-1) as well as major histocompatibility (MHC) I and II genes (Supplementary Table 3, Fig. 5). Among the most up-regulated genes are CD93, CD163, CD209, TNFRSF9, IFI44, IRF7 or viperin while the most down-regulated genes are CD44, CD248A, TNFSF10L, PKR1 or NFKBIZ.

Regarding the response to stress, we identified 23 genes from the 


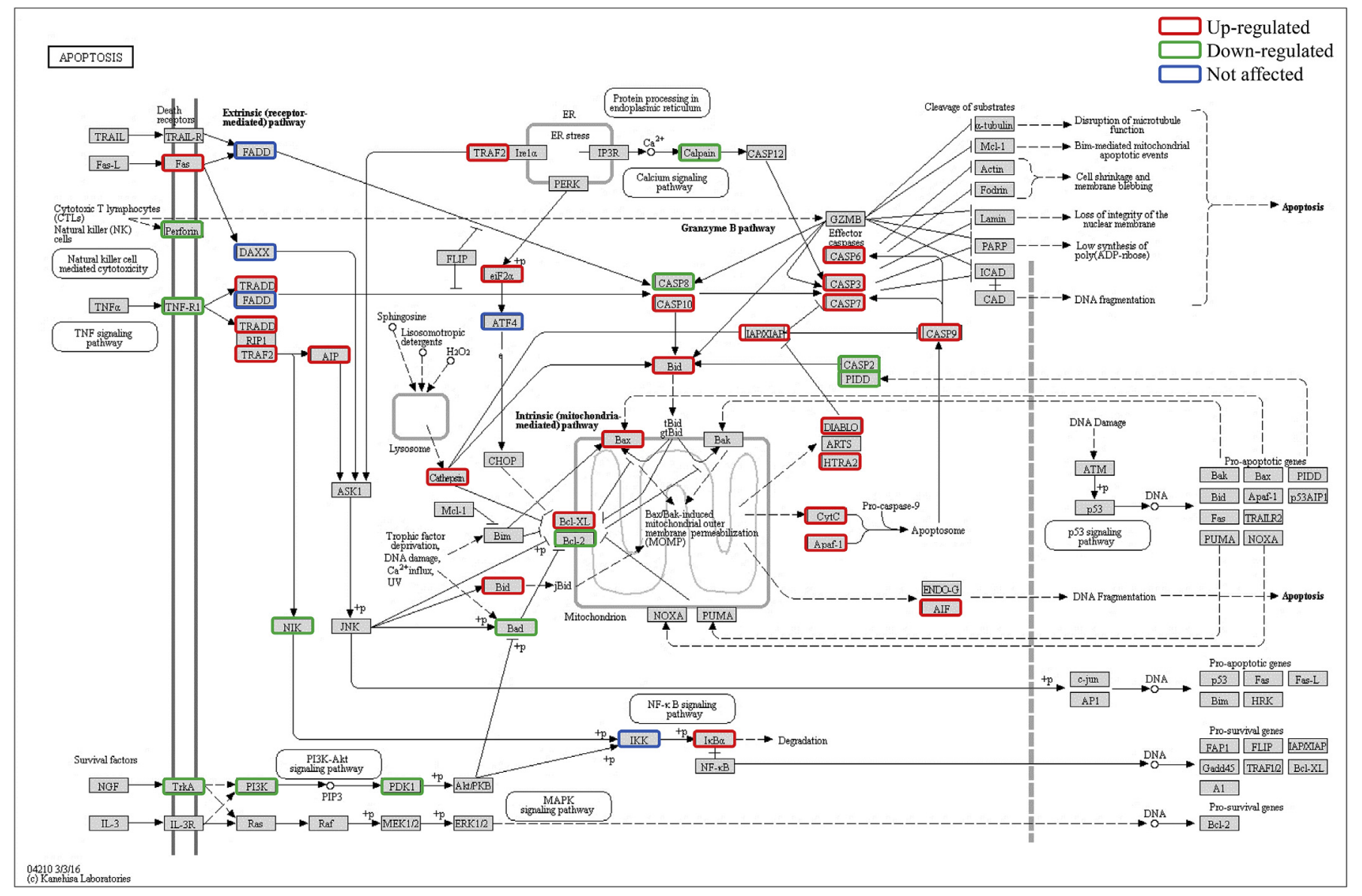

Fig. 6. Identification and regulation of genes related to the KEGG apoptotic pathway (KEGG hsa04210 pathway) in the DLB-1 cells infected with NNV.

heat-shock protein families (HSP70, HSP90, small HSP, chaperonins and DNAJ families) (Table 2), almost all of them up-regulated after NNV infection as well as 29 tripartite motif (TRIM) family of proteins, related to autophagy, apoptosis, immunity or carcinogenesis, that are involved in the proteasome biology. Among those genes in the GO term of cell death, many genes were identified in the KEGG apoptosis pathway (Fig. 6). Thus, genes encoding proteins that favor apoptosis cell death, such as Fas, TRAF2, AIP, Bid, Bax, CASP3, CASP6, CASP7, CASP9, CASP10, CytC, DIABLO or Apaf-1 were shown to be up-regulated by NNV infection, pointing to this cell death mechanism as the most important in DLB-1 cells. Genes related to immunity, response stress and apoptosis were divided into up- and down-regulated to evaluate protein-protein interaction networks by STRING. Data show tight clusters in the apoptosis-, IFN- and HSP-related proteins identified after NNV infection (Fig. 7).

\subsection{NNV infection down-regulates GO terms associated to brain and neuronal biology}

The DLB- 1 cell line was ascribed to a glial origin by the gene expression or glial markers ( $g$ fap and coro1a) and by the lack of neuronal ones (map2 and rbfox3) [27]. However, with this more extensive transcriptomic study, markers to both of them were clearly identified (nestin, coro1a, map2, rbfox3, cd86, cd40, synaptophysin or stathmin among others) (Supplementary Table 3).

We further investigated the GO terms related to brain and neuronal biology in fish after NNV infection for the first time. To this regard, very few GO terms (with a very low number of counts) were found significantly altered after $12 \mathrm{~h}$ of infection or up-regulated at $72 \mathrm{~h}$ of infection (Supplementary Table 4). However, in DLB-1 cells infected with
NNV for $72 \mathrm{~h}$, GO enrichment analysis detected significant down-regulation of processes such as neurogenesis ( 87 terms), neuron differentiation (77 terms), brain development (53 terms), regulation of neuron projection development (13 terms), hindbrain development (17 terms), neural nucleus development ( 8 terms), neural tube formation ( 7 terms) and some other minor represented GO terms (Supplementary Table 4). These transcripts were identified and protein-protein interactions showed a tight interaction among some of the proteins after STRING analysis (Fig. 8). They were mainly related to cytoskeleton or vesicle trafficking.

\section{Discussion}

Nodavirus results in serious outbreaks both in wild and cultured fish species and its distribution and animal susceptibility is continuously expanding. To further research NNV characterization, more tools for its diagnostics, prophylaxis and treatment, at both research and applied levels, are necessary. Thus, the generation of cell lines susceptible to NNV infections are valuable tools that fulfil all these applications. Although several cell lines supporting NNV infection have been generated from fish tissues, very few are available from the actual target tissues, namely the brain and retina. We have characterized a brain cell line derived from the European sea bass, DLB-1 [27], for its capacity to support NNV replication. Although DLB-1 cells were identified as glial cells, the transcriptomic profile described herein suggests they are neuron stem cells, as documented for other fish brain derived cell lines $[35,36]$. Previous studies have demonstrated that fish cell lines derived from fish brain tissues [21-26] are susceptible to RGNNV genotypes, the only one tested. Our results clearly demonstrate that all the NNV genotypes are able to infect the DLB- 1 cell line and produce CPE at 

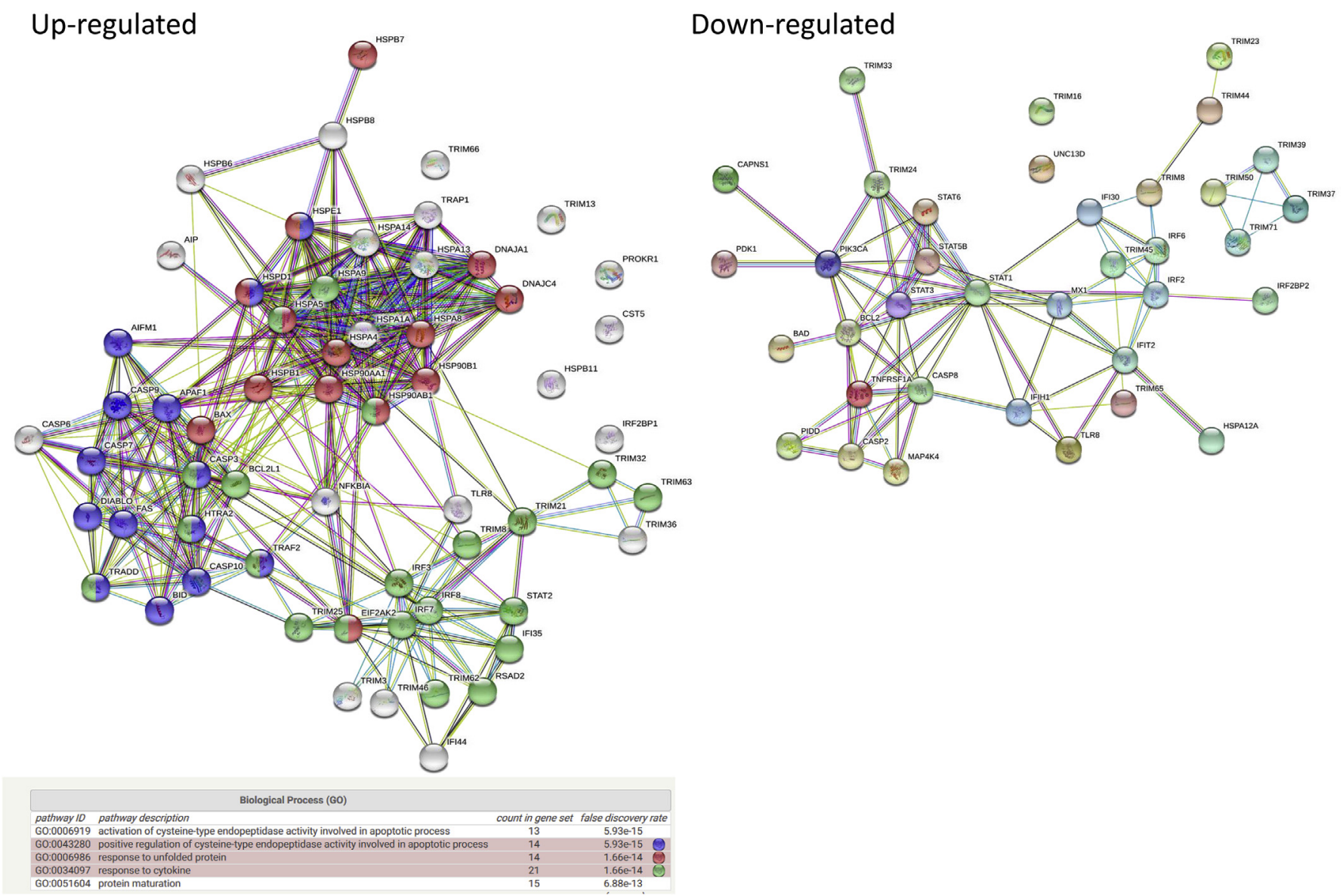

Fig. 7. Protein-protein network interactions of major genes related to immunity, apoptosis and response to stress. STRING analysis for the up-regulated (A) and down-regulated (B) genes in DLB-1 cells infected with NNV.

$25^{\circ} \mathrm{C}$, although the RGNNV strain replicated to the highest extent. The time-course infection results in the appearance of CPE around $72 \mathrm{~h}$ of infection as established for these viruses in other cell lines. Unexpectedly, both BFNNV and TPNNV strains seemed not to replicate in DBL-1 cell line at $20^{\circ} \mathrm{C}$, which is considered their optimal growth temperature in E-11 cell line (Iwamoto et al., 2003). Further studies will be necessary to establish the reasons of the different response to temperature in both cell lines. Although this study has used the reference RGNNV isolate SGWak97 more studies should be performed to ascertain the benefits of this cell line for virological studies and to further characterize host-NNV interactions in brain tissue with other isolates.

In the last decade the evaluation of host-NNV interactions by -omic technologies has proven to be very useful at gene level, leading to the description of pivotal transcripts involved in fish cell-NNV interactions [16-20]. Top up-regulated genes in the European sea bass brain DLB1 cell line infected with NNV was the heat-shock protein 70 (HSP70). Heat-shock proteins, called molecular chaperons, are a heterogeneous group of proteins induced under stress situations, leading to protein denaturation, such as heat, nutrient deficiency, oxidative stress, pollution, inflammatory diseases and viral or bacterial infections [37]. Besides HSP70, many other members of the HSP family were also significantly up-regulated upon NNV infection. Similarly, other studies have also identified the implication of HSP-members upon NNV challenge such as HSP30, HSP70 and HSP90 in either fish cell lines or brain $[18-20,38]$. These proteins are involved in protein folding and translocation, avoiding protein denaturation and degradation of misfolded proteins and have an important role in viral infections [39]. On the one hand, they are involved in correct antigenic presentation by the MHC I or II, that favors a proper immunity, and on the other they ensure a proper formation of the viral proteins and the capsid formation, leading to the new virus progeny to be infective. Interestingly, HSC70 was also up-regulated in DLB-1 cells infected with NNV. This protein has been clearly related to NNV binding and entry into fish cells, since HSC70 was detected in the cellular membrane of grouper GF-1 cell lines and NNV entry was blocked by incubation with HSC70 antibodies [8], in a similar way to other mammalian viruses [39]. Interestingly, some other HSPs, such as HSP70 or glucose-regulated protein (GRP) $78 / \mathrm{BiP}$, though not its primary location site, are present in the cellular membrane and involved in virus binding and entry as well as targeting the infected cell for immune cell recognition [20,39,40]. GRPs, mainly present in the endoplasmic reticulum (ER), are greatly involved in the response against RNA virus, GRP78/BiP being one of the most important and first sensors of protein misfolding, whose interaction with folded proteins acts as positive feedback for stress responses. Thus, we detected up-regulation of GRP75, GRP94, but mainly GRP78/BiP, in NNV-infected DLB-1 cells. This is confirmed by previous studies detecting the increased expression of GRP78 upon NNV infection as well as its interaction and co-localization with NNV CP and RdRP proteins $[19,41]$. These data point to the importance of the HSPs during viral infections and deserves further characterization to understand the hostvirus crosstalk, as well as their relationship with other affected cellular processes, such as immunity or apoptosis.

Immune-related genes in DLB-1 cells were also up-regulated upon NNV-infection, indicating that DLB-1 cells recognize and respond to NNV infection, but the immune response triggered is not efficient enough, because the viruses replicate and kill the cells. For example, regarding the IFN response against viruses, some of the key elements were identified as DEGs in the RNA-seq analysis. Strikingly, some important IFN genes were down-regulated by NNV infection (IFIH1/MDA5, PKR1, 


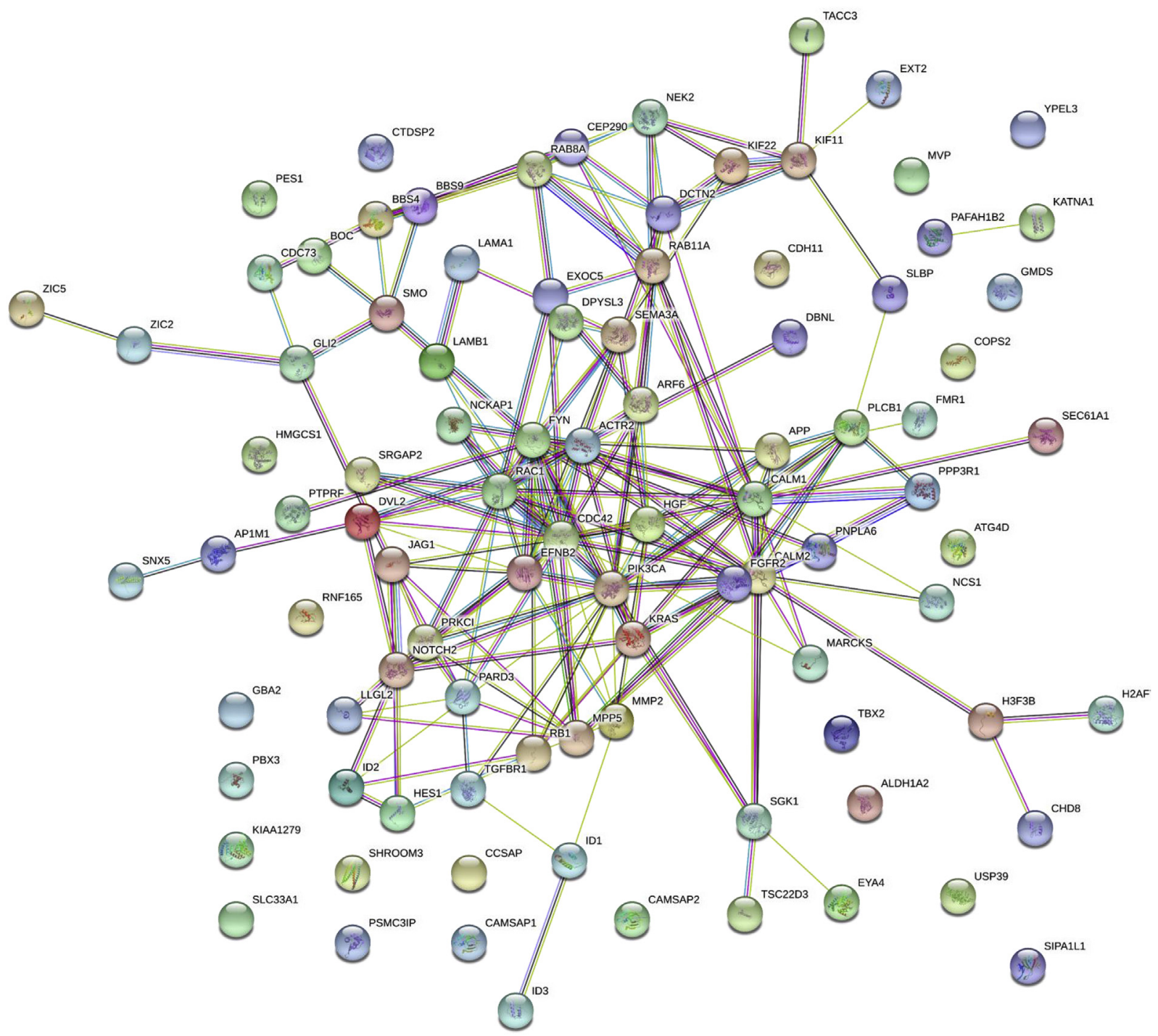

Fig. 8. Protein-protein network interactions of major genes related to brain and neuron development and function found down-regulated in DLB-1 cells infected with NNV for $72 \mathrm{~h}$

IFI44, IFI30, IFIT2 or IRF2BP2) while others, although up-regulated, were decreased during the NNV infection time (Mx, TANK, IFI35) indicating a response decay. Although some of these genes have been detected in previous studies using transcriptomic analysis [18,20,42], the relationship between the transcription of IFN-related genes and the viral susceptibility/resistance of fish cells is not clearly stated. Thus, individual overexpression of genes encoding fish MDA5 [43], MAVS [44], TBK1 [45], Mx [46] or ISG15 [47] has resulted in increased resistance to NNV infections, whereas in the case of LGP2 [48], this resulted in increased viral susceptibility. In addition, we demonstrated that upon RGNNV strain infection, genes related to the IFN pathway were induced during the infection time in the resistant fish species gilthead seabream but generally decreased in the brain of the very susceptible European sea bass [49], pointing to a clear lack of correlation between the IFN response and effective cellular response in susceptible fish species, which merits deeper analysis. Additionally, regarding CD markers, CD44, CD226 and CD276 are involved in natural killer and lymphocyte activation while CD93, CD163 or CD209 are in endocytosis and phagocytosis processes and their expression suggest a macrophage activation and lymphocyte reduction. This is partly confirmed by the increased expression of macrophage-related genes such as SLC1, MRC1 or MARCKSL1B as well as of the IL1B, the main proinflammatory cytokine, and some interleukin receptors. Though there is not much information at this respect it is known that fish infection by virus, including NNV, induces IL1B production and activates macrophages at either functional or transcriptomic levels [50-52]. Interestingly, though we failed to find the transcript for TNFa we found many TNFa-related genes significantly regulated. Thus, genes coding for TRAF2, TRAF3, and mainly TNFRSF9, are up-regulated, which might lead to immunostimulation via NF-kB pathway. However, NF-kB seems not to be up-regulated as suggested by the low alteration of their regulated immune genes and the up-regulation of NFKBIAA, one of its inhibitors. Then, TNF-related genes would be favouring the apoptosis, the other cellular effects they mediate. In this regard, Fas, TNFAIP3, TNFAIP8, TNFAIP8L2B and TNFAIP8L3, known positive regulators of apoptosis are also up-regulated suggesting that this TNF pathway is more related to apoptosis than to immunity. Taking into consideration all these findings DLB-1 cells are infected by RGNNV and regulate genes involved in different immune responses though further functional studies would be necessary to ascertain their role in host-NNV interactions.

As a consequence of the HSP family expression and inefficient immune response, NNV replicates causing cell apoptosis, as previously demonstrated [11,13-15,17,19,22,53]. NNV infection up-regulated genes related to both intrinsic and extrinsic apoptosis cell death in DLB1 cells, leading to dysregulation in the balance of pro/anti-apoptotic factors and the up-regulation of several caspases. The TRIM family of 
proteins are well-known important players during disease and are involved in autophagy, immunity and carcinogenesis because they act as targeting proteins to the proteasome degradation machinery but also as regulators of many cellular pathways $[54,55]$. Interestingly, though we detected some TRIM genes, we failed to clearly detect an important upregulation of their expression, suggesting that proteins synthetized during infection are kept in the right folding state, probably due to the overexpressed HSPs, guaranteeing the proper formation of infective NNV particles. Moreover, this could be related to the lack of autophagy of NNV proteins, since no significant alteration of major genes involved in autophagy, such as akt genes, was detected. Although this autophagy has been documented for some other fish viruses [56-58], no such observations have been documented in the case of NNV. In addition, little up-regulation of genes encoding TRIM21, TRIM23 and TRIM25 was observed, which might be related to the immune response. For example, TRIM23 and TRIM25 act upon several mediators of the IFN pathway leading to its activation, though TRIM21 does the opposite [55]. Overexpression studies of fish TRIMs have shown that TRIM8, TRIM39 or TRIM47 increase IFN response and/or viral resistance [59-61], though TRIM13 reduces them [62]. Thus, further studies are needed to ascertain the interactions between different pathways and their particular correspondence to the final cellular response or phenotype.

Regarding the central nervous system, the target tissue for NNV replication and disease, none of the transcriptomic studies after NNV infection have focused on the identification of GO terms related to brain or neuronal biology. Interestingly, we found significant down-regulations in DLB-1 cells after $72 \mathrm{~h}$ of infection with NNV. Most of the transcripts identified were related to the cytoskeleton and vesicle biology, very important pathways for neurons. For example, STRING analysis showed interaction between Zinc finger proteins such as ZIC5, ZIC2 or GLI2. Thus, defects in ZIC2 results in animal disease due to abnormal brain development and neuronal behaviour [63], while its down-regulation results in latent virus reactivation [64]. Regarding proteins with the highest interactions, we found down-regulation of RAC1, a member of the Rho family of GTPases, an essential player in the neuronal cytoskeleton that regulates synaptic spines through actin polymerization [65]. For its part, FYN is a tyrosine-protein kinase that plays a role in many biological processes including cytoskeletal remodelling and neuronal migration, myelination, synaptic plasticity and the regulation of excitatory and inhibitory receptors [66] and also acts by regulating Rho GTPases. Other down-regulated proteins with strong connections and key functions on neuronal biology found in DLB-1 cells infected with NNV are EFNB2, ACTR2, PARD3, SRGAP2, LAMB1, NCKAP1, APP, FGFR2, SEMA3A, most of them involved in cytoskeleton and vesicle formation/transport in neurons. These data suggest that the failure of vesicle transport upon NNV infection could be a major mechanism behind the pathogenic effects on the fish nervous system. Further studies are needed to ascertain the implications of NNV infection in the brain at molecular levels.

In conclusion, the European sea bass brain DLB-1 cell line is susceptible to nodavirus replication, especially to the RGNNV genotype. Transcriptome analysis reveals an important induction of genes related to heat-shock protein, immunity, apoptosis, but not autophagy, while genes related to cellular metabolism, cell cycle and cytoskeleton were down-regulated, suggesting that the virus changes the cell machinery to its benefit to produce infective particles. Interestingly, it is the first time we found the down-regulation of pathways leading to a normal brain and neuronal development and behaviour, which might explain the pathogenic effects on the nervous system. This information describes the valuable tool generated to understand fish-NNV interactions with potential applicability in the field of fish aquaculture.

\section{Acknowledgments}

This work was supported by grants of the National Bioinformatics
Institute (INB), PRB2-ISCIII (PT13/0001/0044 to JG and AE); MINECO (PTA2014-09515 to MD), MINECO and FEDER (AGL2013-43588-P and AGL2016-74866-C3-1-R to AC and AGL2014-54532-C2-2-R to IB), Instituto Español de Oceanografía (NODAMED) and Fundación Séneca (Grupo de Excelencia de la Región de Murcia 19883/GERM/15).

Data availability. The annotation produced in this study can be downloaded from http://denovo.cnag.cat/genomes/seabass/where we provide also a JBrowse with tracks for all the RNAseq and data used to annotate the genome. The data discussed in this publication have been deposited in NCBI's Gene Expression Omnibus and are accessible through GEO Series accession number GSE118060.

\section{Appendix A. Supplementary data}

Supplementary data related to this article can be found at https:// doi.org/10.1016/j.fsi.2018.11.024.

\section{References}

[1] Q.K. Doan, M. Vandeputte, B. Chatain, T. Morin, F. Allal, Viral encephalopathy and retinopathy in aquaculture: a review, J. Fish. Dis. (2016), https://doi.org/10.1111/ jfd.12541.

[2] OIE, Viral encephalopathy and retinopathy, World Organ. Anim. Heal. 2017 Man. Diagnostic Test Aquat. Anim.

[3] T. Nishizawa, M. Furuhashi, T. Nagai, T. Nakai, K. Muroga, Genomic classification of fish nodaviruses by molecular phylogenetic analysis of the coat protein gene, Appl. Environ. Microbiol. 63 (1997) 1633-1636.

[4] G.N. Frerichs, H.D. Rodger, Z. Peric, Cell culture isolation of piscine neuropathy nodavirus from juvenile sea bass, Dicentrarchus labrax, J. Gen. Virol. 77 (1996) 2067-2071, https://doi.org/10.1099/0022-1317-77-9-2067.

[5] T. Iwamoto, T. Nakai, K. Mori, M. Arimoto, I. Furusawa, Cloning of the fish cell line SSN-1 for piscine nodaviruses, Dis. Aquat. Org. 43 (2000) 81-89, https://doi.org/ 10.3354/dao043081.

[6] S.C. Chi, W.W. Hu, B.J. Lo, Establishment and characterization of a continuous cell line (GF-1) derived from grouper, Epinephelus coioides (Hamilton): a cell line susceptible to grouper nervous necrosis virus (GNNV), J. Fish. Dis. 22 (1999) 173-182, https://doi.org/10.1046/j.1365-2761.1999.00152.x.

[7] W. Liu, C.-H. Hsu, Y.-R. Hong, S.-C. Wu, C.-H. Wang, Y.-M. Wu, C.-B. Chao, C.S. Lin, Early endocytosis pathways in SSN-1 cells infected by dragon grouper nervous necrosis virus, J. Gen. Virol. 86 (2005) 2553-2561, https://doi.org/10.1099/ vir.0.81021-0.

[8] J.-S. Chang, S.-C. Chi, GHSC70 is involved in the cellular entry of nervous necrosis virus, J. Virol. 89 (2015) 61-70, https://doi.org/10.1128/JVI.02523-14.

[9] C.-F. Low, B. Syarul Nataqain, H.-Y. Chee, M.Z.H. Rozaini, M. Najiah, Betanodavirus: dissection of the viral life cycle, J. Fish. Dis. 40 (2017) 1489-1496, https://doi.org/ 10.1111/jfd.12638.

[10] L.-J. Chen, Y.-C. Su, J.-R. Hong, Betanodavirus non-structural protein B1: a novel anti-necrotic death factor that modulates cell death in early replication cycle in fish cells, Virology 385 (2009) 444-454, https://doi.org/10.1016/J.VIROL.2008.11. 048.

[11] Y.-C. Su, L. Reshi, L.-J. Chen, W.-H. Li, H.-W. Chiu, J.-R. Hong, Nuclear targeting of the betanodavirus B1 protein via two arginine-rich domains induces $\mathrm{G} 1 / \mathrm{S}$ cell cycle arrest mediated by upregulation of p53/p21, Sci. Rep. 8 (2018) 3079, https://doi. org/10.1038/s41598-018-21340-x.

[12] B.J. Fenner, R. Thiagarajan, H.K. Chua, J. Kwang, Betanodavirus B2 is an RNA interference antagonist that facilitates intracellular viral RNA accumulation, $\mathrm{J}$. Virol. 80 (2006) 85-94, https://doi.org/10.1128/JVI.80.1.85-94.2006.

[13] Y.C. Su, H.W. Chiu, J.C. Hung, J.R. Hong, Beta-nodavirus B2 protein induces hydrogen peroxide production, leading to Drp1-recruited mitochondrial fragmentation and cell death via mitochondrial targeting, Apoptosis 19 (2014) 1457-1470, https://doi.org/10.1007/s10495-014-1016-x.

[14] Y.-C. Su, J.-L. Wu, J.-R. Hong, Betanodavirus non-structural protein B2: a novel necrotic death factor that induces mitochondria-mediated cell death in fish cells, Virology 385 (2009) 143-154, https://doi.org/10.1016/J.VIROL.2008.11.036.

[15] Y.-C. Su, J.-L. Wu, J.-R. Hong, Betanodavirus up-regulates chaperone GRP78 via ER stress: roles of GRP78 in viral replication and host mitochondria-mediated cell death, Apoptosis 16 (2011) 272-287, https://doi.org/10.1007/s10495-010-0565-x.

[16] E. Sarropoulou, P. Sepulcre, L. Poisa-Beiro, V. Mulero, J. Meseguer, A. Figueras, B. Novoa, V. Terzoglou, R. Reinhardt, A. Magoulas, G. Kotoulas, Profiling of infection specific mRNA transcripts of the European seabass Dicentrarchus labrax, BMC Genomics 10 (2009) 157, https://doi.org/10.1186/1471-2164-10-157.

[17] W. Chen, L. Yi, S. Feng, X. Liu, M. Asim, Y. Zhou, J. Lan, S. Jiang, J. Tu, L. Lin, Transcriptomic profiles of striped snakehead fish cells (SSN-1) infected with redspotted grouper nervous necrosis virus (RGNNV) with an emphasis on apoptosis pathway, Fish Shellfish Immunol. 60 (2017) 346-354, https://doi.org/10.1016/J. FSI.2016.11.059.

[18] S. Dios, L. Poisa-Beiro, A. Figueras, B. Novoa, Suppression subtraction hybridization (SSH) and macroarray techniques reveal differential gene expression profiles in brain of sea bream infected with nodavirus, Mol. Immunol. 44 (2007) 2195-2204, https://doi.org/10.1016/J.MOLIMM.2006.11.017. 
[19] M.-W. Lu, F.-H. Ngou, Y.-M. Chao, Y.-S. Lai, N.-Y. Chen, F.-Y. Lee, P.P. Chiou, Transcriptome characterization and gene expression of Epinephelus spp in endoplasmic reticulum stress-related pathway during betanodavirus infection in vitro, BMC Genomics 13 (2012) 651, https://doi.org/10.1186/1471-2164-13-651.

[20] P. Liu, L. Wang, J. Kwang, G.H. Yue, S.-M. Wong, Transcriptome analysis of genes responding to NNV infection in Asian seabass epithelial cells, Fish Shellfish Immunol. 54 (2016) 342-352, https://doi.org/10.1016/J.FSI.2016.04.029.

[21] Y.-S. Lai, S. Murali, H.-C. Chiu, H.-Y. Ju, Y.-S. Lin, S.-C. Chen, I.-C. Guo, K. Fang, C.Y. Chang, Propagation of yellow grouper nervous necrosis virus (YGNNV) in a new nodavirus-susceptible cell line from yellow grouper, Epinephelus awoara (Temminck \& Schlegel), brain tissue, J. Fish. Dis. 24 (2001) 299-309, https://doi.org/10.1046/ j.1365-2761.2001.00303.x.

[22] J. Tu, W. Chen, X. Fu, Q. Lin, O. Chang, L. Zhao, J. Lan, N. Li, L. Lin, Susceptibility of Chinese perch brain (CPB) cell and Mandarin fish to red-spotted grouper nervous necrosis virus (RGNNV) infection, Int. J. Mol. Sci. 17 (2016), https://doi.org/10. 3390/ijms17050740.

[23] C.M. Wen, Characterization and viral susceptibility of a brain cell line from brownmarbled grouper Epinephelus fuscoguttatus (Forsskål) with persistent betanodavirus infection, J. Fish. Dis. 39 (2016) 1335-1346, https://doi.org/10.1111/jfd.12464.

[24] S. Chi, Y. Wu, T. Cheng, Persistent infection of betanodavirus in a novel cell line derived from the brain tissue of barramundi Lates calcarifer, Dis. Aquat. Org. 65 (2005) 91-98, https://doi.org/10.3354/dao065091.

[25] M.F. Hasoon, H.M. Daud, A.A. Abdullah, S.S. Arshad, H.M. Bejo, Development and partial characterization of new marine cell line from brain of Asian sea bass Lates calcarifer for virus isolation, Vitr. Cell. Dev. Biol. - Anim. 47 (2011) 16-25, https:// doi.org/10.1007/s11626-010-9348-5.

[26] P. Li, L. Zhou, S. Ni, M. Xu, Y. Yu, J. Cai, S. Wei, Q. Qin, Establishment and characterization of a novel cell line from the brain of golden pompano (Trachinotus ovatus), Vitr. Cell. Dev. Biol. - Anim. 52 (2016) 410-418, https://doi.org/10.1007/ s11626-015-9988-6.

[27] P. Morcillo, E. Chaves-Pozo, J. Meseguer, M.Á. Esteban, A. Cuesta, Establishment of a new teleost brain cell line (DLB-1) from the European sea bass and its use to study metal toxicology, Toxicol. Vitro 38 (2017) 91-100, https://doi.org/10.1016/j.tiv. 2016.10.005.

[28] L.J. Reed, H. Müench, A simple method of estimating fifty per cen endpoints, Am. J. Epidemiol. 27 (1938) 493-497, https://doi.org/10.1093/OXFORDJOURNALS.AJE. A118408.

[29] J.G. Olveira, S. Souto, C.P. Dopazo, I. Bandín, Isolation of betanodavirus from farmed turbot Psetta maxima showing no signs of viral encephalopathy and retinopathy, Aquaculture 406-407 (2013) 125-130, https://doi.org/10.1016/J. AQUACULTURE. 2013.05.007.

[30] E. Chaves-Pozo, Y. Valero, A. Esteve-Codina, J. Gómez-Garrido, M. Dabad, T. Alioto, J. Meseguer, M.Á. Esteban, A. Cuesta, Innate cell-cediated cytotoxic activity of European sea bass leucocytes against nodavirus-infected cells: a functional and RNA-seq study, Sci. Rep. 7 (2017) 15396, , https://doi.org/10.1038/s41598017-15629-6.

[31] A. Dobin, C.A. Davis, F. Schlesinger, J. Drenkow, C. Zaleski, S. Jha, P. Batut, M. Chaisson, T.R. Gingeras, STAR: ultrafast universal RNA-seq aligner, Bioinformatics 29 (2013) 15-21, https://doi.org/10.1093/bioinformatics/bts635.

[32] B. Li, C.N. Dewey, RSEM: accurate transcript quantification from RNA-Seq data with or without a reference genome, BMC Bioinf. 12 (2011) 323, https://doi.org/ 10.1186/1471-2105-12-323.

[33] S. Falcon, R. Gentleman, Using GOstats to test gene lists for GO term association, Bioinformatics 23 (2007) 257-258, https://doi.org/10.1093/bioinformatics/ bt1567.

[34] K.J. Livak, T.D. Schmittgen, Analysis of relative gene expression data using realtime quantitative PCR and the $2-\Delta \Delta$ CT method, Methods 25 (2001) 402-408, https://doi.org/10.1006/meth.2001.1262.

[35] A. Servili, M.R. Bufalino, R. Nishikawa, I.S. de Melo, J.A. Muñoz-Cueto, L.E.J. Lee, Establishment of long term cultures of neural stem cells from adult sea bass, Dicentrarchus labrax, Comp. Biochem. Physiol. Part A Mol. Integr. Physiol. 152 (2009) 245-254, https://doi.org/10.1016/j.cbpa.2008.10.018.

[36] C.M. Wen, C.W. Lee, C.S. Wang, Y.H. Cheng, H.Y. Huang, Development of two cell lines from Epinephelus coioides brain tissue for characterization of betanodavirus and megalocytivirus infectivity and propagation, Aquaculture 278 (2008) 14-21, https://doi.org/10.1016/J.AQUACULTURE.2008.03.020.

[37] P. Ikwegbue, P. Masamba, B. Oyinloye, A. Kappo, Roles of heat shock proteins in apoptosis, oxidative stress, human inflammatory diseases, and cancer, Pharmaceuticals 11 (2018) 2, https://doi.org/10.3390/ph11010002.

[38] J.-O. Kim, J.-O. Kim, W.-S. Kim, M.-J. Oh, Characterization of the transcriptome and gene expression of brain tissue in Sevenband grouper (Hyporthodus septemfasciatus) in response to NNV infection, Genes (Basel). 8 (2017), https://doi.org/10.3390/ genes8010031.

[39] M.G. Santoro, C. Amici, A. Rossi, Role of heat shock proteins in viral infection, in: A.G. Pockley, S.K. Calderwood, M.G. Santoro (Eds.), Prokaryotic Eukaryot. Heat Shock Proteins Infect. Dis. Springer, 2010, pp. 51-84.

[40] A.G. Pockley, M. Muthana, S.K. Calderwood, The dual immunoregulatory roles of stress proteins, Trends Biochem. Sci. 33 (2008) 71-79, https://doi.org/10.1016/j. tibs.2007.10.005.

[41] Y.-C. Su, J.-L. Wu, J.-R. Hong, Betanodavirus up-regulates chaperone GRP78 via ER stress: roles of GRP78 in viral replication and host mitochondria-mediated cell death, Apoptosis 16 (2011) 272-287, https://doi.org/10.1007/s10495-010-0565-x.

[42] C.-H. Tso, M.-W. Lu, Transcriptome profiling analysis of grouper during nervous necrosis virus persistent infection, Fish Shellfish Immunol. 76 (2018) 224-232, https://doi.org/10.1016/J.FSI.2018.03.009.

[43] Y. Huang, Y. Yu, Y. Yang, M. Yang, L. Zhou, X. Huang, Q. Qin, Antiviral function of grouper MDA5 against iridovirus and nodavirus, Fish Shellfish Immunol. 54 (2016) 188-196, https://doi.org/10.1016/J.FSI.2016.04.001.

[44] Y. Huang, J. Zhang, Z. Ouyang, J. Liu, Y. Zhang, Y. Hu, X. Huang, Q. Qin, Grouper MAVS functions as a crucial antiviral molecule against nervous necrosis virus infection, Fish Shellfish Immunol. 72 (2018) 14-22, https://doi.org/10.1016/J.FSI. 2017.10.035.

[45] Y. Hu, Y. Huang, J. Liu, J. Zhang, Q. Qin, X. Huang, TBK1 from orange-spotted grouper exerts antiviral activity against fish viruses and regulates interferon response, Fish Shellfish Immunol. 73 (2018) 92-99, https://doi.org/10.1016/J.FSI 2017.12.010.

[46] Y.-M. Chen, Y.-L. Su, P.-S. Shie, S.-L. Huang, H.-L. Yang, T.-Y. Chen, Grouper Mx confers resistance to nodavirus and interacts with coat protein, Dev. Comp. Immunol. 32 (2008) 825-836, https://doi.org/10.1016/J.DCI.2007.12.003.

[47] X. Huang, Y. Huang, J. Cai, S. Wei, Z. Ouyang, Q. Qin, Molecular cloning, expres sion and functional analysis of ISG15 in orange-spotted grouper, Epinephelus coioides, Fish Shellfish Immunol. 34 (2013) 1094-1102, https://doi.org/10.1016/J. FSI. 2013.01.010

[48] Y. Yu, Y. Huang, Y. Yang, S. Wang, M. Yang, X. Huang, Q. Qin, Negative regulation of the antiviral response by grouper LGP2 against fish viruses, Fish Shellfish Immunol. 56 (2016) 358-366, https://doi.org/10.1016/J.FSI.2016.07.015.

[49] Y. Valero, P. Morcillo, J. Meseguer, F. Buonocore, M.A. Esteban, E. Chaves-Pozo, A. Cuesta, Characterization of the IFN pathway in the teleost fish gonad against vertically transmitted viral nervous necrosis virus, J. Gen. Virol. 96 (2015) 2176-2187, https://doi.org/10.1099/vir.0.000164.

[50] L. Poisa-Beiro, S. Dios, H. Ahmed, G.R. Vasta, A. Martínez-López, A. Estepa, J. Alonso-Gutiérrez, A. Figueras, B. Novoa, Nodavirus infection of sea bass (Dicentrarchus labrax) induces up-regulation of galectin-1 expression with potential anti-inflammatory activity, J. Immunol. 183 (2009) 6600-6611, https://doi.org/ 10.4049/jimmunol.0801726.

[51] M. Varela, A. Romero, S. Dios, M. van der Vaart, A. Figueras, A.H. Meijer, B. Novoa, Cellular visualization of macrophage pyroptosis and interleukin-1 $\beta$ release in a viral hemorrhagic infection in zebrafish larvae, J. Virol. 88 (2014) 12026-12040 https://doi.org/10.1128/JVI.02056-14.

[52] C. Carballo, D. Castro, J.J. Borrego, M. Manchado, Gene expression profiles associated with lymphocystis disease virus (LCDV) in experimentally infected Senegalese sole (Solea senegalensis), Fish Shellfish Immunol. 66 (2017) 129-139, https://doi.org/10.1016/J.FSI.2017.04.028.

[53] C.-W. Chang, Y.-C. Su, G.-M. Her, C.-F. Ken, J.-R. Hong, Betanodavirus induces oxidative stress-mediated cell death that prevented by anti-oxidants and zfcatalase in fish cells, PloS One 6 (2011) e25853, , https://doi.org/10.1371/journal.pone. 0025853 .

[54] S. Hatakeyama, TRIM family proteins: roles in autophagy, immunity, and carcinogenesis, Trends Biochem. Sci. 42 (2017) 297-311, https://doi.org/10.1016/j tibs.2017.01.002

[55] K. Ozato, D.-M. Shin, T.-H. Chang, H.C. Morse III, TRIM family proteins and their emerging roles in innate immunity, Nat. Rev. Immunol. 8 (2008) 849-860, https:// doi.org/10.1038/nri2413.

[56] L. Liu, B. Zhu, S. Wu, L. Lin, G. Liu, Y. Zhou, W. Wang, M. Asim, J. Yuan, L. Li, M. Wang, Y. Lu, H. Wang, J. Cao, X. Liu, Spring viraemia of carp virus induces autophagy for necessary viral replication, Cell Microbiol. 17 (2015) 595-605, https://doi.org/10.1111/cmi.12387.

[57] C. Li, X. Fu, Q. Lin, L. Liu, H. Liang, Z. Huang, N. Li, Autophagy promoted infectious kidney and spleen necrosis virus replication and decreased infectious virus yields in CPB cell line, Fish Shellfish Immunol. 60 (2017) 25-32, https://doi.org/10.1016/J. FSI.2016.11.037.

[58] P. Pereiro, A. Romero, P. Díaz-Rosales, A. Estepa, A. Figueras, B. Novoa, Nucleated teleost erythrocytes play an Nk-lysin- and autophagy-dependent role in antiviral immunity, Front. Immunol. 8 (2017) 1458, https://doi.org/10.3389/fimmu.2017. 01458

[59] Y. Wang, M. Kuang, Y. Lu, L. Lin, X. Liu, Characterization and biological function analysis of the TRIM47 gene from common carp (Cyprinus carpio), Gene 627 (2017) 188-193, https://doi.org/10.1016/J.GFNE. 2017.06.017.

[60] W. Wang, Y. Huang, Y. Yu, Y. Yang, M. Xu, X. Chen, S. Ni, Q. Qin, X. Huang, Fish TRIM39 regulates cell cycle progression and exerts its antiviral function against iridovirus and nodavirus, Fish Shellfish Immunol. 50 (2016) 1-10, https://doi.org/ 10.1016/J.FSI.2016.01.016.

[61] Y. Huang, Y. Yu, Y. Yang, M. Yang, L. Zhou, X. Huang, Q. Qin, Fish TRIM8 exerts antiviral roles through regulation of the proinflammatory factors and interferon signaling, Fish Shellfish Immunol. 54 (2016) 435-444, https://doi.org/10.1016/J. FSI.2016.04.138.

[62] Y. Huang, M. Yang, Y. Yu, Y. Yang, L. Zhou, X. Huang, Q. Qin, Grouper TRIM13 exerts negative regulation of antiviral immune response against nodavirus, Fish Shellfish Immunol. 55 (2016) 106-115, https://doi.org/10.1016/J.FSI.2016.05. 029

[63] B. Murillo, N. Ruiz-Reig, M. Herrera, A. Fairén, E. Herrera, Zic2 controls the migration of specific neuronal populations in the developing forebrain, J. Neurosci. 35 (2015) 11266-11280, https://doi.org/10.1523/JNEUROSCI.0779-15.2015.

[64] Y. Lyu, K. Nakano, R.R. Davis, C.G. Tepper, M. Campbell, Y. Izumiya, ZIC2 is essential for maintenance of latency and is a target of an immediate early protein during Kaposi's sarcoma-associated Herpesvirus lytic reactivation, J. Virol. 91 (2017), https://doi.org/10.1128/JVI.00980-17 e00980-17.

[65] S.J. Heasman, A.J. Ridley, Mammalian Rho GTPases: new insights into their functions from in vivo studies, Nat. Rev. Mol. Cell Biol. 9 (2008) 690-701, https://doi. org/10.1038/nrm2476.

[66] R. Knox, X. Jiang, Fyn in neurodevelopment and ischemic brain injury, Dev Neurosci. 37 (2015) 311-320, https://doi.org/10.1159/000369995. 